\title{
STUDY OF THE DYNAMIC LOADING OF THE LOAD- BEARING STRUCTURE OF A FLAT WAGON DURING TRANSPORTATION BY SEA
}

\author{
Oleksij Fomin \\ Department of Wagons and Wagonriage Facilities \\ State University of Infrastructure and Technologies \\ 9 Kyrylivska str., Kyiv, Ukraine, 04071 \\ fomin1985@ukr.net \\ Alyona Lovska \\ Department of Wagons \\ Ukrainian State University of Railway Transport \\ 7 Feierbakh sq., Kharkiv, Ukraine, 61050 \\ alyonaLovskaya.vagons@gmail.com \\ Oleksandr Safronov \\ State Enterprise «Ukrainian Scientific Railway Car Building Research Institute» \\ 33 I. Pryhodko str., Kremenchuk, Ukraine, 39621 \\ safronov@ukrndiv.com.ua \\ Olena Soroka \\ Department of Navigation \\ Danube Institute of the National University "Odessa Maritime Academy» \\ 9 Fanahoriiska str., Izmail, Ukraine, 68600 \\ elkazej@gmail.com
}

\begin{abstract}
To increase the efficiency of combined transportation, the supporting structure of flat wagon has been created. A feature of the wagon is that the sections have a low center of gravity. This solution allows for the transportation of oversized cargo on a flat wagon within the established dimensions. The design of this flat wagon can be used for the carriage of goods not only by main lines, but also in rail and water traffic when transported by rail ferries.

To ensure the safety of transportation of a flat wagon with containers on a railway ferry, their dynamic loading was determined. It is taken into account that a large-capacity container of 1AA standard size is placed on each section. The solution of the mathematical model was carried out in the MathCad software package. The resulting accelerations, as components of the dynamic load, were taken into account when determining the stability of a container on a flat wagon during transportation by a rail ferry. It was found that the stability of the container is ensured at tilt angles up to $25^{\circ}$.

A computer simulation of the dynamic loading of the supporting structure of an articulated flat wagon with containers during transportation by a railway ferry has been carried out. The calculation is implemented in the CosmosWorks software package using the finite element method. The fields of distribution of accelerations relative to the supporting structure of the flat wagon and containers are determined. The maximum percentage of discrepancy between the results of mathematical and computer simulation does not exceed $11 \%$.

The research carried out will contribute to the creation of innovative designs of flat wagons, as well as to increase the efficiency of the operation of combined transport in international traffic.

Keywords: flat wagon, articulated wagon, dynamic loading, container stability, loading simulation, combined transport.
\end{abstract}

DOI: $10.21303 / 2461-4262.2020 .001512$

\section{Introduction}

The increase in foreign economic interstate relations necessitates the development of the transport industry. With the aim of integrating the transport industry into the system of international transport corridors, combined transport has become widespread.

It is known that one of the most promising and widespread transport systems is container shipping. Basically, containers are transported on flat wagons. For this purpose, flat wagons with 
fittings with stops designed for fastening containers are most often used. However, due to the insufficient number of specialized flat wagons for transporting containers, the modernization of universal structures is being carried out.

To increase the efficiency of using flat wagons in traffic, it is possible to put into operation articulated flat wagons. The design of such flat wagons should ensure their versatility, that is, carry out the transportation of various types of cargo under different operating conditions. In addition, when designing new structures of flat wagons, it is necessary to take into account the loads that can act on them when transported as part of combined trains by rail ferries in communication. Another important area in the creation of flat wagons is the possibility of their use to ensure the civil defense of states (transporting military equipment, conducting fire, etc.).

The creation of such structures of flat wagons will help to increase not only the domestic economy, strengthen external relations in the transport services market, but also increase the defense capability of states.

Currently, a wide variety of design features and technology for servicing flat wagons has been created.

An analysis of the structural features of a new generation flat wagon is given in [1]. The supporting structure of the flat wagon can be adjusted in length. This property of the wagon allows for the transportation of cargo of different sizes.

The design features of a flat wagon for transporting containers are highlighted in [2]. The flat wagon has a carrying capacity of 73 tons and can transport containers of standard size 1CC, $1 \mathrm{C}$, and $1 \mathrm{CX}$. However, these structures of flat wagons do not have the ability to transport oversized cargo in height.

Determination of the dynamic loading of the supporting structure of the wagon during transportation by rail ferry is carried out in $[3,4]$. The presented mathematical and computer models, which take into account the movement of the wagon when the rail ferry rolls.

However, the issue of dynamic loading and strength of articulated flat wagons was not considered in these works.

The advantages of using magnesium alloys in the manufacture of load-bearing structures of wagons are highlighted in [5]. Prospects for the introduction of such materials in carriage building have been determined.

The authors indicated the features of the dynamic loading of wagons made of these materials under operating conditions.

Modeling the strength of the bearing structure of a long-base flat wagon is carried out in [6]. The finite element method was used as a calculation. The studies carried out have confirmed the feasibility of the decisions taken when designing the wagon.

Improvement of the supporting structure of a freight wagon is covered in [7]. The results of the calculation of the strength of the load-bearing structure of the wagon in the Lira software environment are given.

However, at the same time, the authors did not carry out mathematical modeling of the dynamic loading of the flat wagon, and when calculating the strength, the standard values of loads were taken into account.

Determination of the dynamic loading of vehicles during longitudinal impact is carried out in [8]. As an investigated parameter, accelerations are considered as components of a dynamic load.

The issue of dynamic loading of vehicles during transportation on a railway ferry was not considered in the work.

The aim of the article is to highlight the features of determining the dynamic loading of the supporting structure of an articulated flat wagon with a low center of gravity during transportation by sea, in particular on a rail ferry. To achieve this aim, the following objectives have been identified:

- to create a supporting structure of an articulated flat wagon with a low center of gravity;

- to carry out mathematical modeling of the process of dynamic loading of the supporting structure of a flat wagon on a ferry;

- to carry out computer simulation of the process of dynamic loading of the supporting structure of a flat wagon on a ferry. 


\section{Creation of the supporting structure of an articulated flat wagon with a low center of gravity}

To increase the efficiency of transportation of goods by rail, including military equipment in compliance with the established dimensions, it is proposed to introduce articulated flat wagons with a lowered center of gravity (Fig. 1). The supporting structure of the flat wagon consists of two sections, which are supported by three model 18-100 bogies.

The supporting structure is designed on the basis of a flat wagon model 13-401. Pivoted beam has box-section. The center and main longitudinal beams are made of I-beams. In the cantilever parts, the main longitudinal beams are reinforced with vertical sheets. Also, in the cantilever parts of the sections, braces are installed for partial unloading of the backbone girder when perceiving a shock load.

From the side of supporting the sections of the supporting structure on the middle trolley, the pivoted beam is replaced by an I-beam (Fig. 2). The interaction of the sections with each other is carried out using a conventional articulation device of the SAC-1 type.

The load-bearing structure of the flat wagon provides for the transportation of heavy containers. For this purpose, hinged fitting stops are installed in the console parts.

For fastening military equipment, the supporting structure of the flat wagon can be equipped with wheel stops and other multi-turn devices.

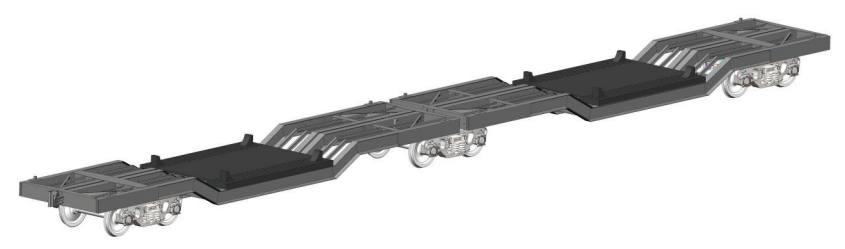

$a$

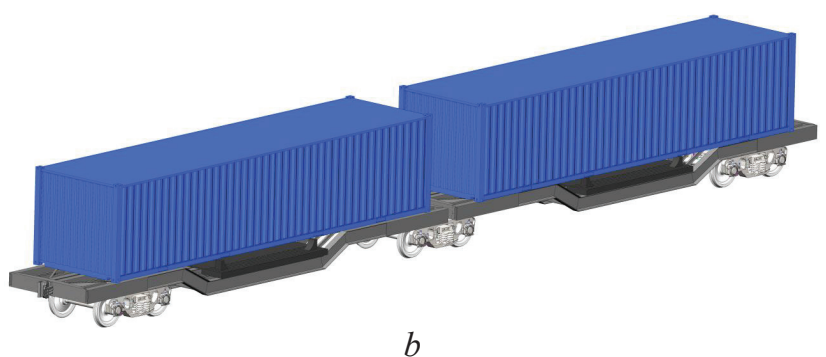

$b$

Fig. 1. An articulated flat wagon with a low center of gravity: $a$ - in an empty state; $b$ - loaded

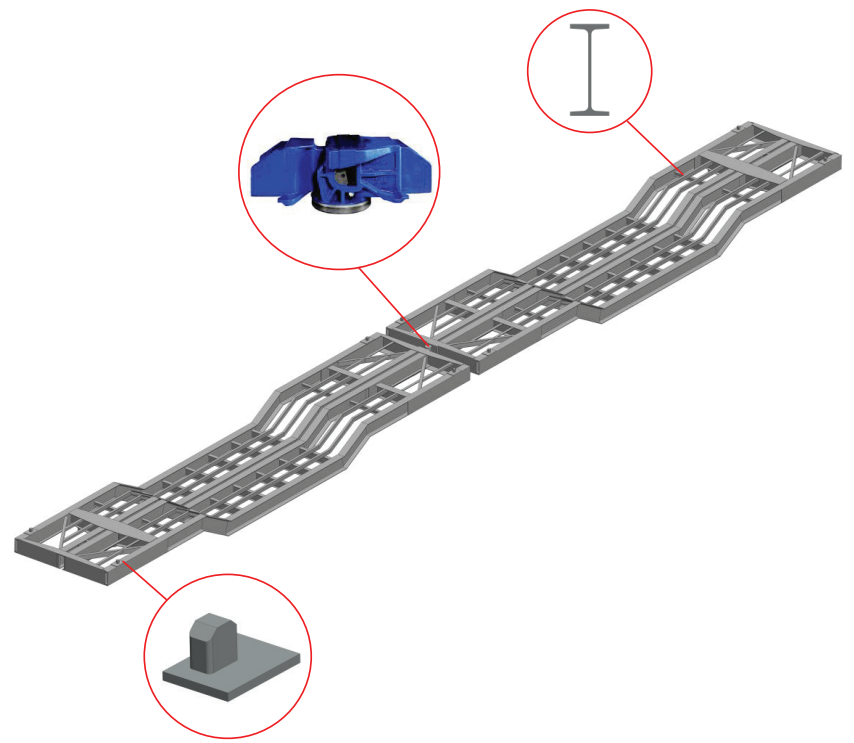

Fig. 2. The supporting structure of an articulated flat wagon with a low center of gravity

In the middle of the sections, sectors are provided for placing military equipment with the possibility of conducting fire effects when the flat wagon moves relative to the main tracks.

\section{Mathematical modeling of the process of dynamic loading of the supporting structure of a flat wagon on a ferry}

To make it possible to transport a flat wagon as part of a combined train on a railway ferry, a mathematical model is compiled: 


$$
\left\{\begin{array}{l}
\left(\frac{D}{12 \cdot g}\left(B^{2}+4 z_{g}^{2}\right)\right) \ddot{q}_{1}+\left(\Lambda_{\theta} \cdot \frac{B}{2}\right) \dot{q}_{1}=p_{Z P}^{\prime} \cdot \frac{h}{2}+\Lambda_{\theta} \cdot \frac{B}{2} \cdot \dot{F}(t), \\
I_{F W}^{\theta} \cdot \ddot{q}_{2}=p_{F W}^{\prime} \cdot \frac{h_{F W}}{2}+M_{F W}^{D}+M_{F W}^{C}, \\
I_{C}^{\theta} \cdot \ddot{q}_{3}=p_{C}^{\prime} \cdot \frac{h_{C}}{2}+M_{C}^{F W},
\end{array}\right.
$$

where $q_{1} \approx \theta_{F}$ - generalized coordinate, corresponds to the angular displacement around the longitudinal axis of the railway ferry; $q_{2} \approx \theta_{W}$ - generalized coordinate, corresponds to angular displacement around the longitudinal axis of the flat wagon; $q_{3} \approx \theta_{C}$ - generalized coordinate, corresponds to the angular displacement around the longitudinal axis of the container. The origin of the coordinate system is located at the center of mass of the rail ferry.

For rail ferry: $D$ - weight water displacement; $B$ - width; $h$ - board height; $\Lambda_{\theta}$ - coefficient of resistance to vibrations; $z_{g}$ - coordinate of the center of gravity; $p_{Z P}^{\prime}$ - wind load on the surface projection; $F(t)$ - the law of the action of the force, which excites the movement of the railway ferry with the wagons placed on its decks.

For a flat wagon with containers: $I_{f w}^{\theta}-$ moment of inertia of the flat wagon; $h_{f w}$ - the height of the side surface of the flat wagon; $p_{f w}^{\prime}$ - wind load on the side surface of the flat wagon; $M_{F W}^{D}-$ moment of forces arising between the flat wagon and the deck of the railway ferry during angular displacements relative to the longitudinal axis; $M_{F W}^{C}-$ moment of forces arising between the flat wagon and the containers during angular displacements relative to the longitudinal axis; $I_{C}^{\theta}-$ moment of inertia of the container; $h_{C}$ - height of the side surface of the container; $p_{C}^{\prime}$ - wind load on the side surface of the container; $M_{C}^{F W}$ - moment of forces arising between the container and the flat wagon during angular displacements relative to the longitudinal axis.

The model takes into account the oscillations of the railway ferry about the longitudinal axis, that is, the roll [9]. At the same time, it was assumed that the roll is caused by the static effect of the wind on the surface projection of the railway ferry, determined by the method of S. Blagoveshchenskyi [10]:

$$
\theta=\operatorname{arctg} \frac{M r}{D \cdot h}
$$

where $D$ - vessel water displacement; $h$ - transverse metacentric height; $M_{r}$ - roll moment.

The roll moment is determined:

$$
M_{r m}=F\left(z_{c}+\frac{T}{2}\right)
$$

where $F$ - wind pressure on the lateral projection of the ship's surface; $z_{v}$-distance from the center of gravity of the vessel's surface projection of the current waterline; $T$ is the draft of the vessel.

The formula is used to determine the transverse metacentric height:

$$
h=z_{m}-z_{g}
$$

where $z_{m}$ - transverse metacentre applicant.

The distance from the center of gravity of the surface of the vessel to the current waterline is calculated:

$$
z_{w}=\frac{S_{1} z_{1}+S_{2} z_{2}+\ldots+S_{n} z_{n}}{S_{1}+S_{2}+\ldots+S_{n}}
$$

where $S_{1}, S_{2}, \ldots, S_{m}$ - areas of the figures into which the lateral projection of the surface of the vessel is divided; $z_{1}, z_{2}, \ldots, z_{n}$ - distance from the centers of gravity of the areas $\mathrm{S}$ of the acting waterline. 
Wind pressure on the lateral projection of the ship's surface is determined:

$$
F=f \cdot S,
$$

where $f$ - wind pressure per unit surface area of the vessel.

For the Black Sea, $f=150 \mathrm{~kg} / \mathrm{m}$ can be taken.

Taking into account the hydrometeorological data of the Black Sea water area and the technical characteristics of the «Heroi Shipki» type railway ferry, the roll angle was $12.2^{\circ}$. The calculations were carried out taking into account the use of the full carrying capacity of the railway ferry. It is taken into account that a 1AA container is placed on each section of the flat wagon.

Also, when determining accelerations as components of dynamic load acting on a flat wagon with containers, various angles of the sea wave in relation to the vessel's hull were taken into account:

$$
\chi=\left\{\begin{array}{l}
0^{\circ} ; \\
30^{\circ} ; \\
45^{\circ} ; \\
60^{\circ} ; \\
120^{\circ} ; \\
135^{\circ} ; \\
150^{\circ} ; \\
180^{\circ} .
\end{array}\right.
$$

The system of differential equations (1) was solved in the MathCad software package. Initial displacements and speeds are taken equal to zero [11-13].

The calculation results are shown in Fig. 3, 4.

The acceleration value is given without taking into account the horizontal component of the gravitational acceleration. The total acceleration acting on the supporting structure of the flat wagon is $3.47 \mathrm{~m} / \mathrm{s}^{2}$, and on the container $-4.673 .47 \mathrm{~m} / \mathrm{s}^{2}$

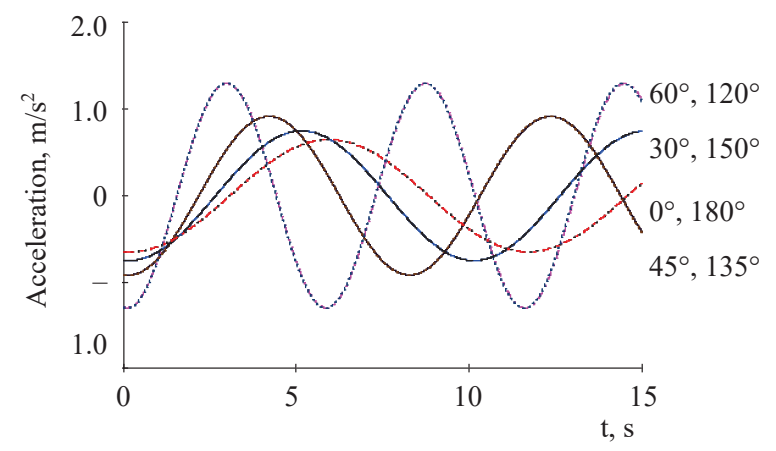

Fig. 3. Acceleration acting on the supporting structure of a flat wagon

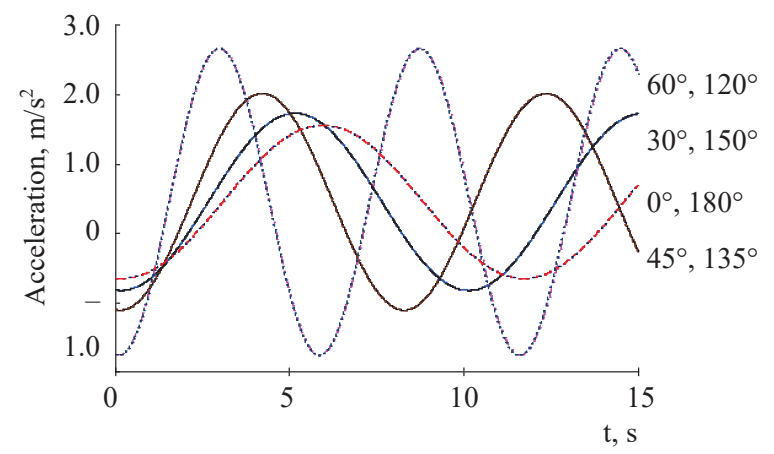

Fig. 4. Acceleration acting on the container 
The resulting accelerations were taken into account when determining the stability of the container equilibrium relative to the flat wagon frame.

In this case, the stability condition has the form:

$$
k_{c}=\frac{M_{\text {res }}}{M_{\text {over }}} \geq 1
$$

where $M_{\text {res }}$ - the value of the restoring moment; $M_{\text {over }}$ - the value of the overturning moment.

The results of the calculations are shown in Table 1.

Table 1

The results of determining the equilibrium stability of the container relative to the frame of the flat wagon

\begin{tabular}{lllllll}
\hline Roll angle, degrees & $\mathbf{5}$ & $\mathbf{1 0}$ & $\mathbf{1 5}$ & $\mathbf{2 0}$ & $\mathbf{2 5}$ & $\mathbf{3 0}$ \\
\hline Stability coefficient & 3.5 & 2.3 & 1.6 & 1.25 & 1.05 & 0.8
\end{tabular}

Table 1 shows that the stability of the container is provided at tilt angles up to $25^{\circ}$.

\section{Computer simulation of the dynamic loading process of the supporting structure of a flat wagon on a ferry}

To determine the fields of distribution of accelerations relative to the supporting structure of a flat wagon with containers placed on it, a computer simulation is carried out. The calculation is carried out using the finite element method in the CosmosWorks software package [14-16].

When compiling the finite element model, isoparametric tetrahedrons are used. The optimal number of elements is determined by the graphic-analytical method [17-20]. The number of mesh elements is $1,589,028$, nodes - 536,801. The maximum element size is $104.4 \mathrm{~mm}$, the minimum $20.8 \mathrm{~mm}$. The maximum aspect ratio of the elements is 413.49 . The percentage of elements with an aspect ratio of less than three -33.1 , more than $10-19.8$. The number of elements in a circle is 8 . The ratio of increasing the size of an element is 1.6.

The design model of the supporting structure of a flat wagon is shown in Fig. 5. It is taken into account that the load-bearing structure of the flat wagon is subject to the vertical load from the gross weight of the containers $P_{v}$, as well as the load from the radar chain ties $P_{c h}$. Since the chain ties have a spatial arrangement, the load that is transmitted through them to the supporting structure of the flat wagon is decomposed into components. The container is subjected to a vertical-static load, as well as a wind ripple.

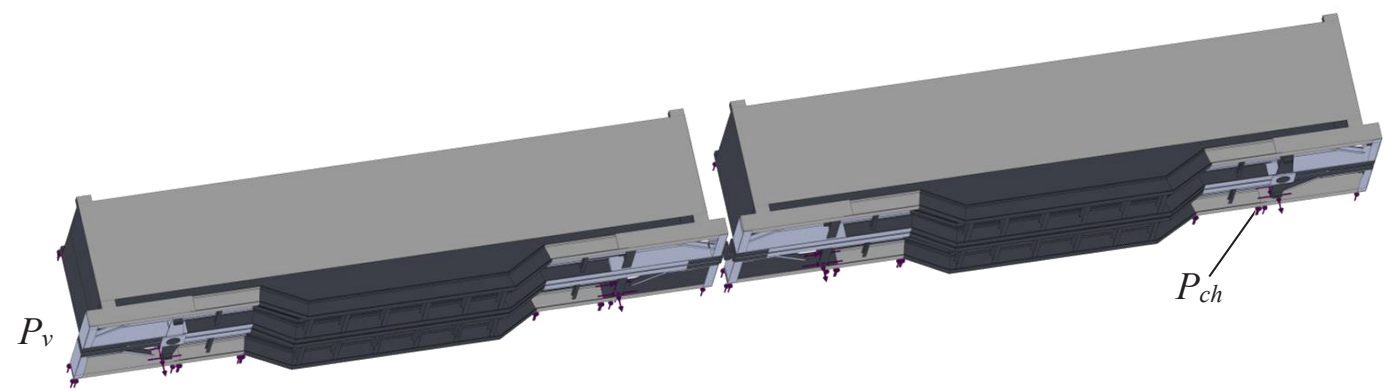

Fig. 5. Design model of the supporting structure of a flat wagon with containers

The fixing of the model is carried out in the zones of bearing on the carts and the working surfaces of the mechanical stop-jacks. Construction material - steel grade 09G2S.

The results of the calculations are shown in Fig. 6.

It has been established that the maximum container accelerations are concentrated in the upper corner parts along the central axis of symmetry of the flat wagon and are about $4.8 \mathrm{~m} / \mathrm{s}^{2}$. 
The maximum accelerations of the supporting structure of the flat wagon occur in the cantilever parts of the sections and amount to about $3.7 \mathrm{~m} / \mathrm{s}^{2}$.

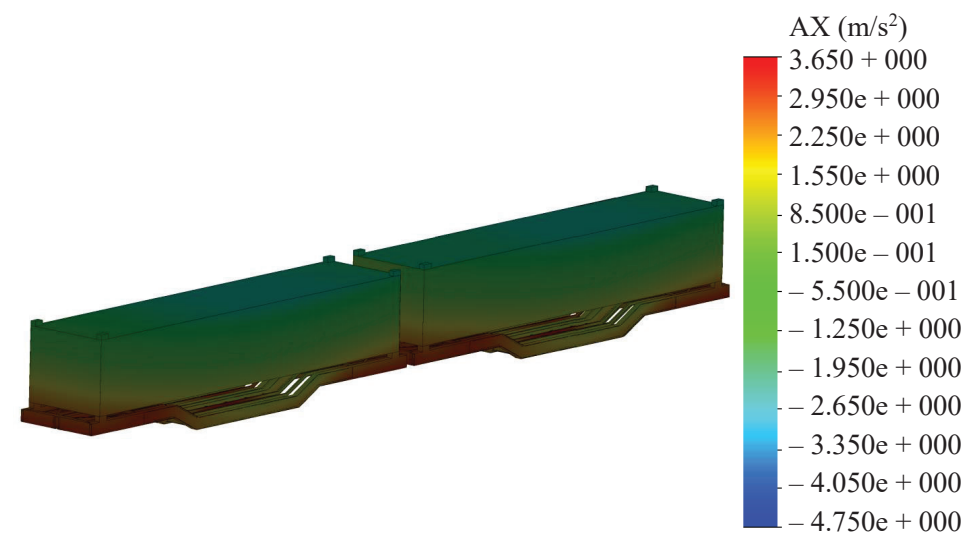

Fig. 6. Distribution of acceleration fields relative to the supporting structure of a flat wagon with containers

The percentage of disagreements between the results of mathematical and computer simulation of the dynamic loading of a flatcar and containers are shown in Fig. 7. The calculations are given taking into account the comparisons of the acceleration of the flat wagon and the containers obtained for different roll angles of the railway ferry. In this case, the «» marker in the Fig. 7 denotes the results obtained for the flat wagon, and $\langle\mathbf{\Delta} »-$ for the container.

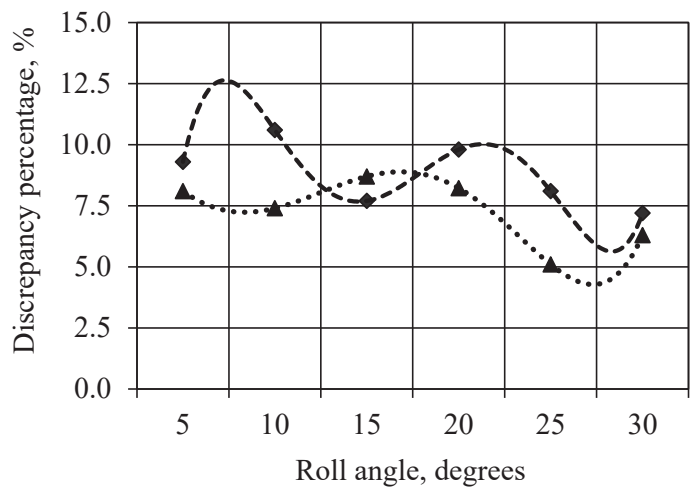

Fig. 7. Discrepancy between the results of mathematical and computer simulation of the dynamic loading of a flat wagon and containers

The calculations made allow to conclude that the maximum percentage of discrepancy between the results of mathematical and computer simulation does not exceed $11 \%$.

\section{Discussion of the results of the study of the dynamic loading of the supporting structure of the flat wagon}

The refined dynamic loads of the bearing structure of an articulated flat wagon with low center of gravity and containers placed on it during transportation by a railway ferry have been obtained.

For this, a mathematical model has been drawn up, given in Chapter 3. The model takes into account the angular displacements of the railway ferry around the longitudinal axis. It was found that the total value of acceleration acting on the supporting structure of the flat wagon is $3.47 \mathrm{~m} / \mathrm{s}^{2}$, and on the container $-4.67 \mathrm{~m} / \mathrm{s}^{2}$.

It is important to note that the above mathematical model does not take into account the shock action of waves on the surface projection of the railway ferry.

The admissible roll angle at which the stability of the container equilibrium relative to the flat wagon frame is ensured is determined. 
To confirm the results obtained mathematically, a computer simulation of the dynamic loading of a flat wagon with containers during transportation by a railway ferry was carried out. The fields of distribution of accelerations relative to their structures are determined. It was found that the maximum acceleration occurs in the upper part of the container structure. The maximum acceleration of the flat wagon occurs in the cantilever parts of the frame. It was found that the maximum discrepancy between the results of mathematical and computer simulation does not exceed $11 \%$.

In further studies in this direction, it is necessary to conduct an experimental determination of the dynamic loading of the load-bearing structures of flat wagons with containers during transportation on railway ferries.

The results obtained can contribute to the creation of recommendations for the safe transportation of containers as part of combined trains on rail ferries. Also, studies have been carried out that can be useful developments and additions to regulatory documents covering the issues of dynamic loading and strength of wagons under operating conditions [21, 22].

\section{Conclusions}

The supporting structure of an articulated flat wagon with a low center of gravity has been created. The supporting structure of the flat wagon consists of two sections supported by three bogies. The presence of a lowered middle part allows transportation of oversized cargo on a flat wagon in compliance with the established dimensions. In the cantilever parts of the flat wagon, hinged fitting stops are installed for fastening containers. For fastening military equipment, the supporting structure of the flat wagon can be equipped with wheel stops and other multi-turn devices.

To determine the dynamic loading of a flat wagon with containers, mathematical modeling was carried out. The maximum accelerations acting on the supporting structure of a flat wagon and a container during transportation by a railway ferry have been determined. The results obtained were taken into account when determining the stability of the container equilibrium. It has been established that the stability of the container is ensured at roll angles of the rail ferry up to $25^{\circ}$.

Computer simulation of the process of dynamic loading of the supporting structure of an articulated flat wagon during transportation on a railway ferry has been carried out. The calculations were performed using the CosmosWorks software package. It was found that the maximum percentage of discrepancy between the results of mathematical and computer simulation does not exceed $11 \%$.

The results obtained can contribute to the creation of recommendations for the design of combined transport vehicles.

Also, studies have been carried out to improve the safety of transportation of flat wagons with containers on railway ferries by sea and the efficiency of the functioning of combined transport in international traffic.

\section{Acknowledgement}

This publication was made within the framework of the project «Development of conceptual frameworks for restoring the efficient operation of obsolete freight wagons» (Project registration number: 2020.02/0122), funded by the National Research Fund of Ukraine for state budget funds.

\section{References}

[1] WBN Waggonbau Niesky GmbH: Developing a flexible platform of freight wagons (2016). Intern. Edition, 1, 46.

[2] Switching over to the home platform (2015). Journal for partners Transmashholding, 3, 22-23.

[3] Lovska, A., Fomin, O., Píštěk, V., Kučera, P. (2019). Dynamic load computational modelling of containers placed on a flat wagon at railroad ferry transportation. Vibroengineering PROCEDIA, 29, 118-123. doi: https://doi.org/10.21595/vp.2019.21132

[4] Fomin, O., Lovska, A., Píštěk, V., Kučera, P. (2019). Dynamic load effect on the transportation safety of tank containers as part of combined trains on railway ferries. Vibroengineering PROCEDIA, 29, 124-129. doi: https://doi.org/10.21595/vp.2019.21138

[5] Lee, W. G., Kim, J.-S., Sun, S.-J., Lim, J.-Y. (2016). The next generation material for lightweight railway car body structures: Magnesium alloys. Proceedings of the Institution of Mechanical Engineers, Part F: Journal of Rail and Rapid Transit, 232 (1), 25-42. doi: https://doi.org/10.1177/0954409716646140

[6] Kel'rich, M., Fedosov-Nikonov, D. (2016). The strength research of the long-wheelbase flatcar construction. Visnyk Skhidnoukrainskoho Natsionalnoho universytetu imeni Volodymyra Dalia, 1 (225), 90-94. 
[7] Vatulia, G., Komagorova, S., Pavliuchenkov, M. (2018). Optimization of the truss beam. Verification of the calculation results. MATEC Web of Conferences, 230, 02037. doi: https://doi.org/10.1051/matecconf/201823002037

[8] Zamecnik, J., Jagelcak, J. (2015). Evaluation of Wagon Impact Tests by Various Measuring Equipment and Influence of Impacts on Cargo Stability. Communications - Scientific Letters of the University of Zilina, 17 (4), 21-27.

[9] Fomin, O., Lovska, A., Radkevych, V., Horban, A., Skliarenko, I., Gurenkova, O. (2019). The dynamic loading analysis of containers placed on a flat wagon during shunting collisions. ARPN Journal of Engineering and Applied Sciences, 14 (21), 3747-3752. Available at: http://www.arpnjournals.org/jeas/research_papers/rp_2019/jeas_1119_7989.pdf

[10] Blagoveshchenskiy, S. N., Holodilin, A. N. (1975). Spravochnik po statike i dinamike korablya. Vol. 2. Dinamika (kachka) korablya. Leningrad.

[11] Kučera, P., Píštěk, V. (2017). Testing of the mechatronic robotic system of the differential lock control on a truck. International Journal of Advanced Robotic Systems, 14 (5), 172988141773689. doi: https://oi.org/10.1177/1729881417736897

[12] Kondratiev, A. V., Gaidachuk, V. E., Kharchenko, M. E. (2019). Relationships Between the Ultimate Strengths of Polymer Composites in Static Bending, Compression, and Tension. Mechanics of Composite Materials, 55 (2), 259-266. doi: https:// doi.org/10.1007/s11029-019-09808-x

[13] Fomin, O., Kulbovsky, I., Sorochinska, E., Sapronova, S., Bambura, O. (2017). Experimental confirmation of the theory of implementation of the coupled design of center girder of the hopper wagons for iron ore pellets. Eastern-European Journal of Enterprise Technologies, 5 (1 (89)), 11-18. doi: https://doi.org/10.15587/1729-4061.2017.109588

[14] Reyes, A. (2018). Beginners guide to SolidWorks 2018. SDC Publications, 2018.

[15] Fomin, O., Lovska, A., Pistek, V., Kucera, P. (2020). Research of stability of containers in the combined trains during transportation by railroad ferry. mm Science Journal, 2020 (1), 3728-3733. doi: https://doi.org/10.17973/mmsj.2020_03_2019043

[16] Fomin, O., Lovska, A. (2020). Improvements in passenger car body for higher stability of train ferry. Engineering Science and Technology, an International Journal. doi: https://doi.org/10.1016/j.jestch.2020.08.010

[17] Vatulia, G. L., Lobiak, O. V., Deryzemlia, S. V., Verevicheva, M. A., Orel, Y. F. (2019). Rationalization of cross-sections of the composite reinforced concrete span structure of bridges with a monolithic reinforced concrete roadway slab. IOP Conference Series: Materials Science and Engineering, 664, 012014. doi: https://oi.org/10.1088/1757-899x/664/1/012014

[18] Pistek, V., Klimes, L., Mauder, T., Kucera, P. (2017). Optimal design of structure in rheological models: an automotive application to dampers with high viscosity silicone fluids. Journal of Vibroengineering, 19 (6), 4459-4470. doi: https:// doi.org/10.21595/jve.2017.18348

[19] Dižo, J., Steišūnas, S., Blatnický, M. (2016). Simulation Analysis of the Effects of a Rail Vehicle Running with Wheel Flat. Manufacturing Technology, 16 (5), 889-896. doi: https://oi.org/10.21062/ujep/x.2016/a/1213-2489/mt/16/5/889

[20] DSTU 7598:2014. Vahony vantazhni. Zahalni vymohy do rozrakhunkiv ta proektuvannia novykh i modernizovanykh vahoniv koliyi $1520 \mathrm{~mm}$ (nesamokhidnykh) (2015). Kyiv, 162.

[21] GOST 33211-2014. Freight wagons. Requirements to structural strength and dynamic qualities (2016). Moscow, 54. Available at: http://docs.cntd.ru/document/1200121493

[22] EN 12663-2. Railway applications - structural requirements of railway vehicle bodies - Part 2: Freight wagons (2010).

Received date 10.04.2020

Accepted date 10.11.2020

Published date 30.11.2020
(C) The Author(s) 2020

This is an open access article under the CC BY license (http://creativecommons.org/licenses/by/4.0). 